\begin{tabular}{|l|l|r|}
\hline A1 Fitrah & Meningkatkan Kreativitas Anak Sebagai \\
Journal Of Early Childhood Islamic Education & Optimalisasi Perkembangan \\
ISSN : 2599-2287 E-ISSN : 2622-335X & Komprehensif AUD \\
& Asiyah \\
\hline
\end{tabular}

\title{
MENINGKATKAN KREATIVITAS ANAK SEBAGAI OPTIMALISASI PERKEMBANGAN KOMPREHENSIF ANAK USIA DINI
}

\begin{abstract}
Abstrak
Education is the process of changing one's attitude or behavior groups of people to mature humans through teaching and training efforts. Since early humans have needed education in the process of its development into adulthood. The development of children in the first years is very important and will determine the quality in the future. Children are individuals who are different, unique, and have their own characteristics in accordance with the stages of his age. Therefore, early childhood development efforts should be done through learning and play. Growth and physical development have an important role in the lives of children. Growth and physical development is one of the major developmental tasks in the life of a child. Growth and physical development will affect the development and growth of children in other developmental dimensions. Parents and teachers really need to understand the growth and physical development of children, and instill healthy habits through physical activity of children from an early age.To help the physical development of children, teachers and parents need to provide guidance to them in order to have the awareness of sensory abilities, and also have a positive attitude towards him. Parents and teachers also need to understand the signs of developmental delays in children, parents and teachers need to be cautious in view of delays in child development and should consult with your doctor to make sure and give the child needed help, so that children can grow physically and develop optimally.
\end{abstract}

Keywords: physical development, early childhood

Asiyah
asiyah@iainbengkulu,ac.id

IAIN Bengkulu

\section{Pendahuluan}

Manusia sebagai makhluk pasif dan aktif, dengan kepasifannya (yang mengalami perkembangan secara alami) maka lingkungan berkesempatan untuk mendidik dan menyediakan sarana prasarana untuk mengenal alam semesta agar teraktual sisi kemanusiaannya. Sedangkan keaktifan manusia menjadi semangat untuk mencari pengetahuan tentang banyak hal di alam semesta ini, karena manusia telah memiliki potensi daya-daya yang harus dioptimalkan untuk memenuhi kebutuhannya sebagai makhluk individu dan sosial. Kebutuhan berinteraksi memberikan kesempatan pada manusia untuk saling mencontoh, meskipun setiap tahapan usia memiliki sifat dan tugas 


\begin{tabular}{|l|l|r|}
\hline A1 Fitrah & Meningkatkan Kreativitas Anak Sebagai \\
\hline Journal Of Early Childhood Islamic Education & Optimalisasi Perkembangan \\
ISSN : 2599-2287 E-ISSN : 2622-335X & Komprehensif AUD \\
Vol.2 No.1 Juli 2018 & Asiyah \\
\hline
\end{tabular}

perkembangan yang berbeda-beda. Untuk anak usia dini yang masih dalam perkembangan kognitif pra operasional maka membutuhkanyang telah dimiliki manusia dapat berkembang secara optimal, maka dibutuhkan upaya-upaya dari lingkungan eksternal serta semangat dari faktor internal (dengan memahami kelebihan dan kelemahan) untuk memenuhi kebutuhan pribadi dan tuntutan sosial. Sehingga menjadi manusia yang berkembang sempurna untuk menghadapi kompetisi pada fase berikutnya (remaja, dewasa, tua, dan lansia). Karena kesuksesan perkembangan selanjutnya. (Farida : 2014).

Perkembangan adalah perubahan psikologis sebagai hasil dari proses pematangan fungsi psikis dan fisik pada diri anak, yang ditunjang oleh faktor lingkungan dan proses belajar dalam peredaran waktu tertentu menuju kedewasaan dari lingkungan yang banyak berpengaruh dalam kehidupan anak menuju dewasa. (Hamdi : 2011)

Perkembangan merupakan suatu proses yang tidak akan pernah berakhir dan berhenti. Setiap saat manusia mengalami perkembangan (Developmental) baik berupa perkembangan fisik maupun mental. Hakikat dari perkembangan adalah sebagai proses yang tidak pernah berhenti dan berakhir (never ending process).

Perkembangan dapat diartikan perubahan yang agresif dan kontinu (berkesinambungan) dalam diri individu dari mulai lahir sampai mati. Syamsu Yusuf (2005) mengungkapkan bahwa perkembangan individu adalah perubahanperubahan yang dialami individu atau organisme menuju tingkat kedewasaannya atau kematangannya (maturation) yang berlangsung secara sistematis, progresif, dan berkesinambungan baik menyangkut fisik maupun psikis.

Anak usia dini bertumbuh dan berkembang menyeluruh secara alami. Jika pertumbuhan dan perkembangan tersebut dirangsang maka akan mencapai. Aspek perkembangan motorik merupakan salah satu aspek perkembangan yang dapat mengintegrasikan perkembangan aspek yang lain (Ike Ayu Suryaningrum : 2015).Menurut UU Nomor 20 Tahun 2003 Bab I Pasal 1 Ayat 14 tentang pendidikan bahwa: Pendidikan anak usia dini adalah suatu upaya pembinaan yang ditujukan kepada anak sejak lahir sampai dengan usia enam tahun yang dilakukan melalui pemberian rangsangan pendidikan untuk membantu pertumbuhan dan perkembangan jasmani dan rohani agar anak memiliki kesiapan dalam memasuki pendidikan lebih lanjut. Pendidikan anak usia dini (early childhoodeducation/PAUD) sangat penting 


\begin{tabular}{|l|l|r|}
\hline & Al Fitrah & Meningkatkan Kreativitas Anak Sebagai \\
Journal Of Early Childhood Islamic Education & Optimalisasi Perkembangan \\
ISSN : 2599-2287 E-ISSN : 2622-335X & Komprehensif AUD \\
Vol.2 No.1 Juli 2018 & Asiyah \\
\hline
\end{tabular}

dilaksanakan sebagai dasar bagi pembentukan kepribadian manusia secara utuh, yaitu pembentukan karakter, budi pekerti luhur, cerdas, ceria, terampil, dan bertakwa, kepada Tuhan yang Maha Esa. (Permendiknas Nomer 58 : 2009).Peraturan Menteri Pendidikan Nasional Republik Indonesia Nomor 58 tahun 2009 menyatakan bahwa "Tujuan Pendidikan Taman Kanak-kanak adalah membantu anak didik mengembangkan berbagai potensi baik psikis dan fisik yang meliputi lingkup perkembangan nilai agama dan moral, fisik/motoric, kognitif, bahasa, serta sosial emosional kemandirian”. (Permendiknas Nomer 58 : 2009).

\section{Pembahasan}

Perkembangan merupakan suatu proses yang bersifat komulatif, artinya perkembangan terdahulu akan menjadi dasar bagi perkembangan selanjutnya. Menurut Darsinah (2011:5) perkembangan kognitif merupakan perubahan kognitif yang terjadi pada aspek kognitif anak, dimana perubahan ini merupakan suatu proses yang berkesinambungan, mulai dari proses berfikir kogkrit sampai pada konsep yang lebih tinggi yaitu konsep abstrak dan logis.

Perkembangan kognitif berhubungan dengan meningkatnya kemampuan anak berpikir (thinking),memecahkan masalah (problem solving), mengambil keputusan (decision making), kecerdasan (intellingence), bakat (aptitude). Optimalisasi perkembangan kognitif sangat dipengaruhi oleh kematangan fisiologis, terutama pada bayi maupun anak- anak. Seseorang anak akan dapat melakukan koordinasi gerakan tangan, kaki maupun kepala secara sadar, setelah syaraf- syaraf maupun otot- otot bagian organ- organ tersebut sudah berkembang secara memadai. (Rohani : 2016)

Optimalisasi perkembangan pada anak usia dini melalui upaya pembelajaran yang diberikan pada anak perlu disesuaikan dengan taraf dan tugas perkembangannya (Semiawan : 2002). Karena semua anak memang tidak dapat disamakan karena masing-masing mempunyai sifat pembawaan sendiri-sendiri (ciri khas dan keunikan). Sehingga dengan demikian, tidak semua pendidikan untuk anak dapat diterapkan secara mutlak. Namun paling tidak, sifat-sifat dan kebiasaan anak-anak secara umum banyak kesamaannya (Mahfuzh : 2004). Hal tersebut sesuai dengan pendapat Kak Seto Mulyadi bahwa sumber informasi yang terpenting adalah dari sisi anak (yang pada awal kehidupannya dipahami oleh ibu, Montezzori menyebut sebagai sekolah 


\begin{tabular}{|l|l|r|}
\hline A1 Fitrah & Meningkatkan Kreativitas Anak Sebagai \\
Journal Of Early Childhood Islamic Education & Optimalisasi Perkembangan \\
ISSN : 2599-2287 E-ISSN : 2622-335X & Komprehensif AUD \\
Vol.2 No.1 Juli 2018 & Asiyah \\
\hline
\end{tabular}

bahasa Ibu). Sekolah yang baik adalah baik menurut anak bukan baik menurut iklan. Misalnya saat mendaftarkan sekolah, anak diberi kesempatan untuk melihat dan mencoba, jika memang anak merasa "sreg" nyaman barulah orang tua mendaftarkan anak sekolah. Meskipun kenyataannya banyak orang tua memilih sekolah hanya karena keinginan orang tua yang mendasarkan pada prestise (Rakhmawati : 2007) padahal harapan yang ingin diwujudkan dengan bersekolah adalah agar tugas perkembangan dalam setiap fase dapat dilaksanakan dengan optimal oleh si anak. (Farida : 2014)

Salah satu tahap perkembangan yang berlangsung dalam kehidupan manusia adalah tahap usia prasekolah yang berlangsung pada sekitar umur 2-6 tahun. Seperti halnya pada masa bayi, maka pada masa usia pra sekolah ini berbagai aspek perkembangan anak sedang berada pada keadaan perubahan yang sangat pesat, baik dalam kemampuan fisik, motorik, bahasa, kecerdasan, emosi, social dan kepribadian.

Bimbingan perkembangan merupakan usaha pemberian bantuan kepada individu supaya individu tersebut mencapai tugastugas perkembangan. Ahman (1998) berpendapat bahwa pada bimbingan perkembangan lebih menitikberatkan pada kebutuhan, kekuatan, minat dan issue-isue yang berkaitan dengan tahapan perkembangan dan merupakan bagian penting dan integral dari keseluruhan program pendidikan. Bimbingan yang merupakan bagian integral dari pendidikan dikarenakan tujuan akhir dari bimbingan dan pendidikan pada dasarnya sama, yaitu mencapai kedewaaan atau perkembangan yang optimal.

Terdapat beberapa tugas perkembangan yang harus dikuasai oleh anak prasekolah yaitu:1) belajar mengenal perbedaan jenis kelamin dan kesopanan sosial; 2) membentuk konsep-konsep dan belajar berbahasa untuk menggambarkan realitas sosial dan fisik; 3) bersiap-siap untuk membaca; 4) belajar membedakan salah dan benar serta mulai mengembangkan hati nurani (Havighurst dalam Turner dan Helms :1995).

Anak TK (taman kanak kanak) yang pada umumnya berusia 4-6 th diharapkan telah mampu menyelesaikan tugas-tugas perkembangan masa bayi dan sekarang sedang berkembang menuju pencapaian kemampuan dan keterampilan anak usia Sekolah Dasar. Dunia anakpun bertambah luas; ia mulai mengenal dunia lain selain keluarganya. Dalam menuju tahap perkembangan lebih lanjut, anak TK memerlukan orangtua, guru, teman-teman dan lingkungan yang dapat membantunya 


\begin{tabular}{|l|l|r|}
\hline & Al Fitrah & Meningkatkan Kreativitas Anak Sebagai \\
Journal Of Early Childhood Islamic Education & Optimalisasi Perkembangan \\
ISSN : 2599-2287 E-ISSN : 2622-335X & Komprehensif AUD \\
Vol.2 No.1 Juli 2018 & Asiyah \\
\hline
\end{tabular}

untuk mengembangkan segenap potensinya.

(Hamdi : 2011).

Dengan berkembangnya kemampuan bicara, koordinasi sensomotorik dan daya pikir anak, maka seorang anak dapat mengekspresikan semua gagasan yang ada dalam pikiran dan perasaannya baik dalam bentuk verbal, grafis maupun perbuatan.

Torrance mengajukan beberapa saran untukmenciptakan suasana kondusif untuk terjadinya ekspresi kreatif. Antara lain dengan menghormati oertanyaan yang tidak biasa, menghormati ide imajinatif dan kreatif, menunjukkan kepada anak bahwa ide anak memiliki makna, serta menghindari tumbuhnya perasaan takut dinilai pada diri anak.

Terdapat beberapa cara dalam upaya meningkatkan kecerdasan kreativitas anak usia dini :

1. Mengusahakan agara anak tetap sehat

2. Memberi rangsangan pada seluruh indera

3. Memberi peluang agar anak senang bercakap-cakap, membaca, menyanyi, menari.

4. Memberi cukup perhatian, kasih sayang dan rasa aman dalam takaran yang tepat.

5. Terlibat dalam kegiatan anak secara wajar. Usahakan agar anak menjadi pemimpin bagi dirinya sendiri.

6. Memberi kemudahan dalam berbagai sarana untuk mengembangkan kcerdasandan kreativitas.

7. Memberi waktu dan suasana yang memungkinkan anak menyibukkan diri, berimajinasi dan bereksperimen secara aman.

8. Memberi kesempatan bagi anak untuk menyalurkan hasrat ingin tahu dan keinginan menjelajahi dunia luar selain keluarganya serta memberi kesempatan untuk mencoba mengerjakan tugas yang sulit dan mengandung resiko dalam batasan usianya. (Hamdi : 2011)

\section{Penutup}

Perkembangan merupakan suatu proses yang tidak akan pernah berakhir dan berhenti. Setiap saat manusia mengalami perkembangan (Developmental) baik berupa perkembangan fisik maupun mental. Hakikat dari perkembangan adalah sebagai proses yang tidak pernah berhenti dan berakhir (never ending process). Perkembangan dapat diartikan perubahan 


\begin{tabular}{|l|l||r|}
\hline & A1 Fitrah & Meningkatkan Kreativitas Anak Sebagai \\
Journal Of Early Childhood Islamic Education & Optimalisasi Perkembangan \\
ISSN : 2599-2287 E-ISSN : 2622-335X & Komprehensif AUD \\
Vol.2 No.1 Juli 2018 & Asiyah \\
\hline
\end{tabular}

yang agresif dan kontinu (berkesinambungan) dalam diri individu dari mulai lahir sampai mati.

Upaya optimalisasi anak usia prasekolah tidak terlepas dari beberapa aspek yaitu memahami hakikat komprehensif psikologi perkembangan anak prasekolah, pengetahuan dan upaya orang tua dalam meningkatkan kecerdasan serta kreativitas balita, menstimulasi mental anak balita agar berkembang secara baik, dan menstimulasi permainan-permainan bagi anak yang mendidik.

\section{Daftar Pustaka}

Farida. 2014. Upaya Mengoptimalkan Perkembangan Anak Usia Dini, Jurnal Thufula, Vol. 2 No. 1, STAIN Kudus.

Ike Ayu Suryaningrum. 2015. Mengembangkan Ketrampilan Fisik Motorik Halus Anak Melalui Kegiatan Menjahit untuk Usia 5-6 tahun Semester i TK Karangrejo 03 Kecamatan Wungu Kabupaten Madiun Tahun Ajaran 2015/2016, Prosiding Seminar Nasional Pendidikan"Meretas Sukses Publikasi Ilmiah Bidang Pendidikan Jurnal Bereputasi”Kerjasama Program Studi S3 Ilmu Pendidikan, Program Studi S2 Pendidikan Luar Biasa Universitas
Sebelas Maret Surakarta Dan Ispi Wilayah Jawa Tengah, Surakarta : 2015

Rohani. 2016. Mengoptimalkan Perkembangan Kognitif Anak Melalui Kegiatan Bermain, Jurnal Raudhah, Vol. IV, No. 2

Yusuf LN, Syamsu. 2005. Psikologi Perkembangan Anak dan Remaja. Bandung : Rosda Karya.

http://hamdimuhamad.blogspot.co.id/2011/ 07/optimalisasi-perkembangananak.html 